\title{
Wind Hull: Sistema Eólico para Sinalização Integrado ao Capacete Motociclístico
}

\author{
Wind Hull: Wind System for Signaling Integrated into the Motorcycle Helmet
}

STEFANO, Evandro J.; Graduado em Design de Produto; Faculdade de Administração e Artes de Limeira - FAAL

stefano_evandro@yahoo.com.br

SNIKER, Tomas Guner; Doutor em Design e Arquitetura; Faculdade de Administração e Artes de Limeira - FAAL

tsniker@hotmail.com

\section{Resumo}

A sinalização do capacete motociclístico é importante para aumentar a percepção da presença do motociclista por outros condutores no período noturno ou em condições de pouca iluminação solar, proporcionando maior segurança. Atualmente, essa sinalização é realizada pela utilização de elementos retrorrefletivos aplicados na extensão externa do capacete. O presente artigo visa o desenvolvimento de um sistema eólico para sinalização integrado a um capacete de segurança destinado a motociclistas, que possibilite a captação da energia eólica produzida no deslocamento da motocicleta para garantir o funcionamento de luzes de sinalização. O projeto foi baseado em um produto existente no mercado e, com a finalidade de facilitar a utilização do equipamento por seus usuários, foi aprimorado a partir de alguns aspectos considerados negativos, promovendo uma inovação incremental no sistema de sinalização de capacetes motociclísticos.

Palavras Chave: design de produto; sistema eólico e capacete motociclístico.

\begin{abstract}
The motorcycle helmet signaling is important to increase the perception of the motorcyclist's presence by other drivers at night or in conditions of little solar illumination, providing greater safety. Currently, this signaling is performed by the use of retroreflective elements applied to the helmet's outer extension. This article aims at the development of a wind system for signaling integrated into a safety helmet for motorcyclists, which allows the capture of wind power produced in the motorcycle's movement to ensure the operation of signaling lights. The project was based on an existing product in the market and, with the purpose of facilitating the use of the equipment by its users, it was improved from some aspects considered negative, promoting an incremental innovation in the system of motorcycle helmets signaling.
\end{abstract}

Keywords: product design; wind system and motorcycle helmet. 


\section{Introdução}

Nos últimos anos, com o crescente número da frota de motocicletas no Brasil, devido ao melhor custo-benefício e a velocidade para se locomover no lento transito das grandes cidades, aumentou também a necessidade pela utilização dos equipamentos de proteção.

Os equipamentos de proteção são responsáveis por preservar a integridade física dos condutores e passageiros de motocicletas e similares, evitando danos maiores em casos de acidentes. Dentre os equipamentos de proteção essenciais para andar de moto com segurança, podemos considerar o capacete como item principal. A função central deste equipamento é proteger toda a região da cabeça do condutor e passageiro da motocicleta ou similar, prevenindo ou reduzindo os danos e as lesões que poderiam ser causadas em caso de queda e impacto, além de proteger os olhos ao pilotar em velocidade e promover conforto contra frio e chuva.

O capacete também deve contribuir para a sinalização do usuário, por meio de elementos retrorrefletivos aplicados na superfície externa do casco. Em uma pesquisa realizada objetivando levantar dados sobre o público-alvo previsto para o produto, descobriu-se que existe uma parcela de motociclistas que não utilizam os elementos retrorrefletivos nos capacetes, por não saberem a função dos mesmos, por estética ou por outros motivos.

A utilização de elementos retrorrefletivos de segurança é regulamentada pela Resolução 453 do Conselho Nacional de Trânsito (CONTRAN) e sua inadimplência pode acarretar em graves acidentes, pois os materiais retrorrefletivos devolvem à fonte de luz quase toda a luz emitida, tornando o motociclista visível e facilmente reconhecido por outros condutores, mesmo em locais onde a iluminação solar estiver baixa ou ausente.

Atualmente, existe no mercado um modelo de capacete motociclístico com um sistema de luz de LED integrado, no qual as luzes são alimentadas por uma bateria interna, recarregada por meio de um cabo USB. Esse sistema foi desenvolvido pela empresa francesa Shark e exerce a mesma função dos retrorrefletivos. Embora apresente muitas qualidades, o sistema precisa ser recarregado constantemente e durante esse processo, o produto não pode ser utilizado.

Diante deste contexto, o presente artigo apresenta uma proposta de aplicação de um sistema eólico para sinalização integrado a um capacete de segurança destinado a condutores e passageiros de motocicletas, motonetas, ciclomotores, triciclos e quadriciclos motorizados. Por meio da combinação de tecnologias existentes no mercado, propõe a adaptação de um dispositivo (cooler) na extensão frontal do capacete, responsável em captar a energia eólica produzida no deslocamento da motocicleta e converter em energia elétrica. Com isso, realizar sem a necessidade de cabos e fontes externas, o carregamento de uma bateria interna que alimenta um sistema composto por LEDs. A energia luminosa gerada pelos LEDs será utilizada para assegurar a sinalização em cada lado do capacete: frente, atrás, direita e esquerda, conforme Resolução 453 do Conselho Nacional de Trânsito (CONTRAN).

O intuito deste projeto é proporcionar uma melhoria estética e funcional na sinalização de capacetes para motociclistas, substituindo os elementos retrorrefletivos por LEDs, tecnologia amplamente utilizada nos mais diversos tipos de equipamentos e nas mais diversas áreas por ser um sistema de iluminação mais econômico e eficiente, em conjunto com a utilização de uma fonte de energia renovável. 


\section{Método para Levantamento e Análise de Dados}

Para Munari (2015, p. 10), “o método de projeto não é mais do que uma série de operações necessárias, dispostas por ordem lógica, ditada pela experiência. Seu objetivo é o de atingir o melhor resultado com o menor esforço".

O desenvolvimento deste projeto foi embasado no método projetual proposto por Löbach (2001) dividido em quatro fases, sendo elas: preparação, geração, avaliação e realização.

\subsection{Fase de preparação}

Nessa fase de análise do problema, foram coletadas todas as informações necessárias para o desenvolvimento de uma solução, sendo analisados diversos fatores como: necessidade, mercado, funções práticas, estrutura de construção e funções estéticas.

\subsubsection{Análise da necessidade}

Os consumidores considerados como público-alvo para este projeto são os condutores e passageiros de motocicletas e similares, visto que são esses os usuários diretos do produto. $O$ foco principal, são homens e mulheres, com faixa etária entre 20 a 40 anos de idade, que trabalham e possuem renda própria, acostumados com o uso de tecnologia e que utilizam uma motocicleta como meio de locomoção, tanto para o trabalho, como para passeio, principalmente em período noturno.

Com o público-alvo definido, foi elaborado uma pesquisa quantitativa referente aos elementos retrorrefletivos dos capacetes motociclísticos, aplicada por meio de folhetos impressos a um grupo de 100 pessoas pertencentes a esse público, objetivando compreender a visão dos usuários sobre o assunto. Com a aplicação do questionário e a posterior análise dos dados obtidos, foi possível concluir que $24 \%$ dos entrevistados ainda não utilizavam os elementos retrorrefletivos nos capacetes, $14 \%$ não sabiam qual a função dos mesmos e $60 \%$ não os consideravam esteticamente agradáveis.

\subsubsection{Análise do mercado}

Segundo Munari (2015, p. 96) "pode ser útil ao projetista saber como se analisam os objetos de produção industrial, a fim de conhecer suas qualidades e defeitos sob todos os aspectos".

Para aprofundar a compreensão dos capacetes motociclísticos disponíveis no mercado e as formas como atendem às necessidades de seus usuários, foram selecionados para análise 4 produtos similares. Como critério de avaliação dos similares foi utilizada a análise SWOT (dos termos em inglês "Strengths, Weaknesses, Opportunities, Threats"), que consiste em um método de planejamento estruturado no qual avalia quatro elementos de uma organização, projeto ou negócio, sendo esses elementos as forças, fraquezas, oportunidades e ameaças, envolvendo o monitoramento dos ambientes interno e externo. As forças e fraquezas estão relacionadas ao ambiente interno, enquanto as oportunidades e ameaças estão relacionadas ao ambiente externo (KOTLER; KELLER, 2006). 
A análise realizada, possibilitou identificar a inexistência de produtos similares equipados com um sistema eólico para sinalização. O único capacete motociclístico existente no mercado que utiliza LEDs na sinalização é o Skwal da marca Shark, sendo este uma inspiração para o projeto. Foram determinados dois aspectos relevantes, considerados negativos desse principal similar, com a finalidade de estabelecer melhorias ao desenvolvimento do novo sistema integrado ao capacete motociclístico, sendo eles:

- O sistema de luz de LED não abrange as laterais do capacete;

- O sistema de luz de LED depende de uma fonte de energia externa para ser recarregado.

\subsubsection{Análise das funções práticas}

Foram desenvolvidas duas "árvores topográficas", que são representações gráficas detalhadas com a intenção de estruturar e mostrar as características técnicas funcionais do produto, uma destinada ao capacete motociclístico (figura 1) e outra ao sistema eólico (figura 2). Para esse desenvolvimento anotou-se várias funções consideradas inerentes ao produto, de acordo com pesquisas anteriores, decompondo a função principal em suas funções secundárias e as relações de proximidade entre elas, sendo ordenadas logicamente.

\section{Figura 1 - Estrutura funcional de um capacete motociclístico}

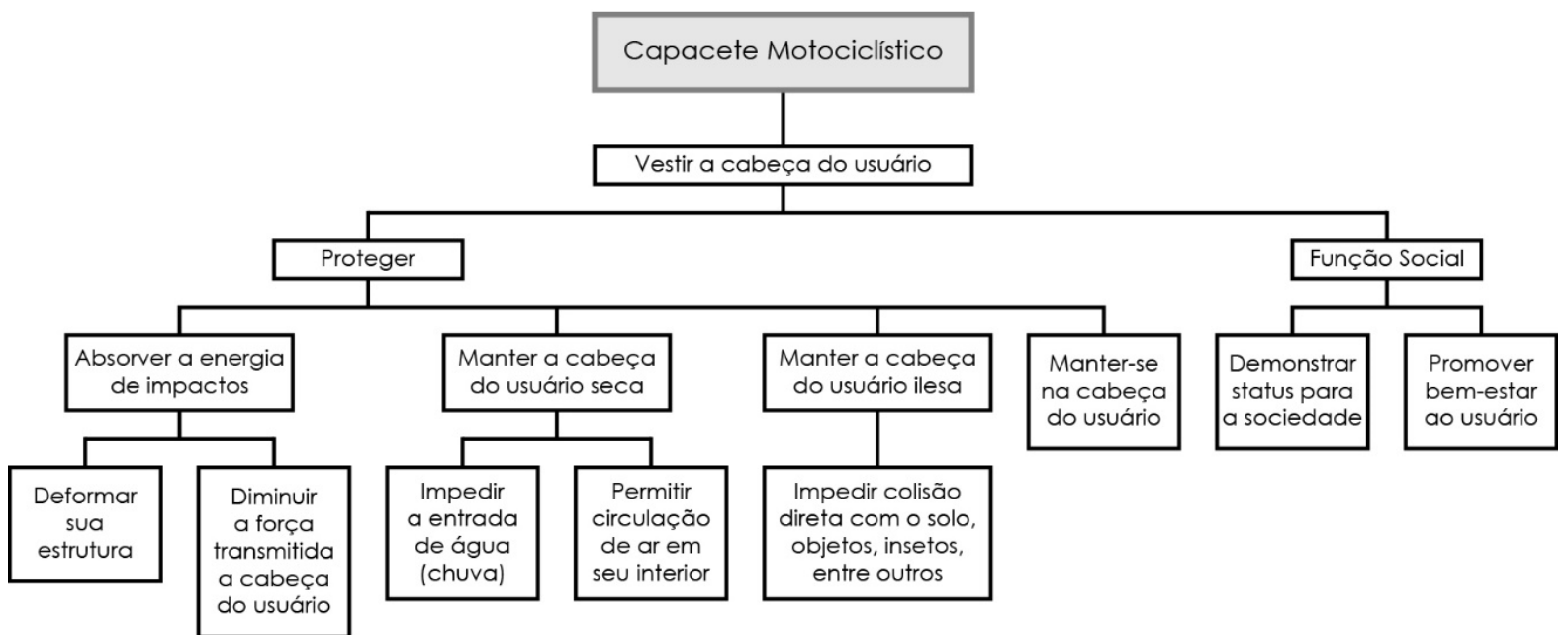

Fonte: o autor 
Figura 2 - Estrutura funcional do sistema eólico para sinalização

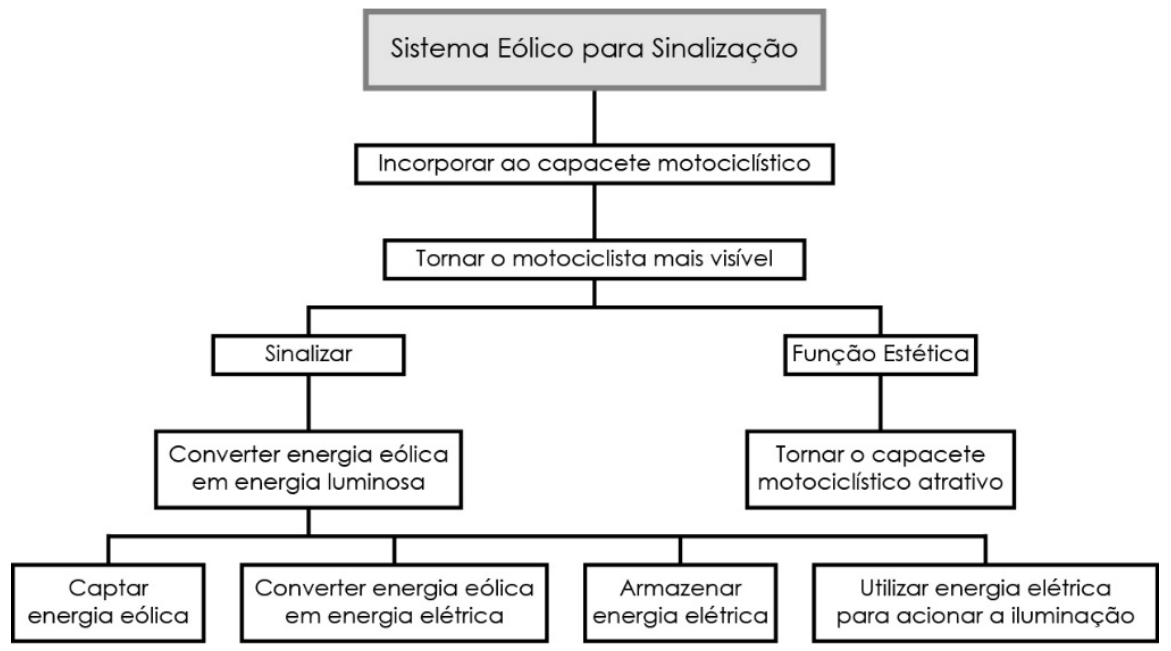

Fonte: o autor

\subsubsection{Análise da estrutura de construção}

Com base na análise estrutural do capacete motociclístico, foi definido que o sistema eólico para sinalização será adaptado na região frontal do capacete, onde se recebe diretamente o vento, mais precisamente na extensão interna do protetor do maxilar, em que existe espaço disponível capaz de comportar o sistema.

A estrutura do sistema eólico responsável por realizar a sinalização do capacete está representada na figura 3 e descrita logo abaixo, conforme seus componentes.

Figura 3 - Estrutura de construção do sistema eólico para sinalização

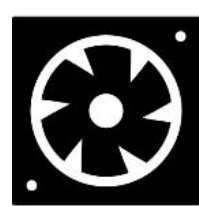

Cooler

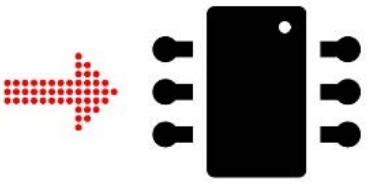

Placa eletrônica

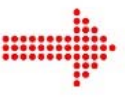

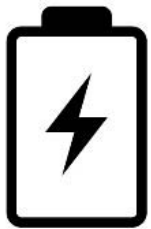

Bateria

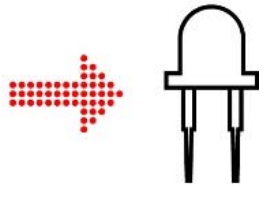

LED

Fonte: o autor

- Cooler: Captar energia eólica e converter em energia elétrica;

- Placa eletrônica: Reduzir a tensão elétrica para carregar a bateria;

- Bateria: Armazenar energia elétrica para alimentar os LEDs;

- LED: Gerar energia luminosa. 


\subsubsection{Análise das funções estéticas}

Para estudo das funções estéticas, foi desenvolvido um painel semântico do tema visual (figura 4), no qual buscou-se representar referências visuais e conceituais que remetam a sofisticação e a inovação, agrupando produtos com características formais, materiais e de qualidade, como cores e acabamentos, semelhantes às pretendidas para o desenvolvimento do projeto. Buscou-se formas limpas, elegantes e fluidas, a predominância de cores neutras e foscas como o preto, o cinza e o branco, cores vivas como o verde fluorescente para os detalhes, texturas lisas de materiais metálicos, plásticos e emborrachados.

Figura 4 - Painel do tema visual
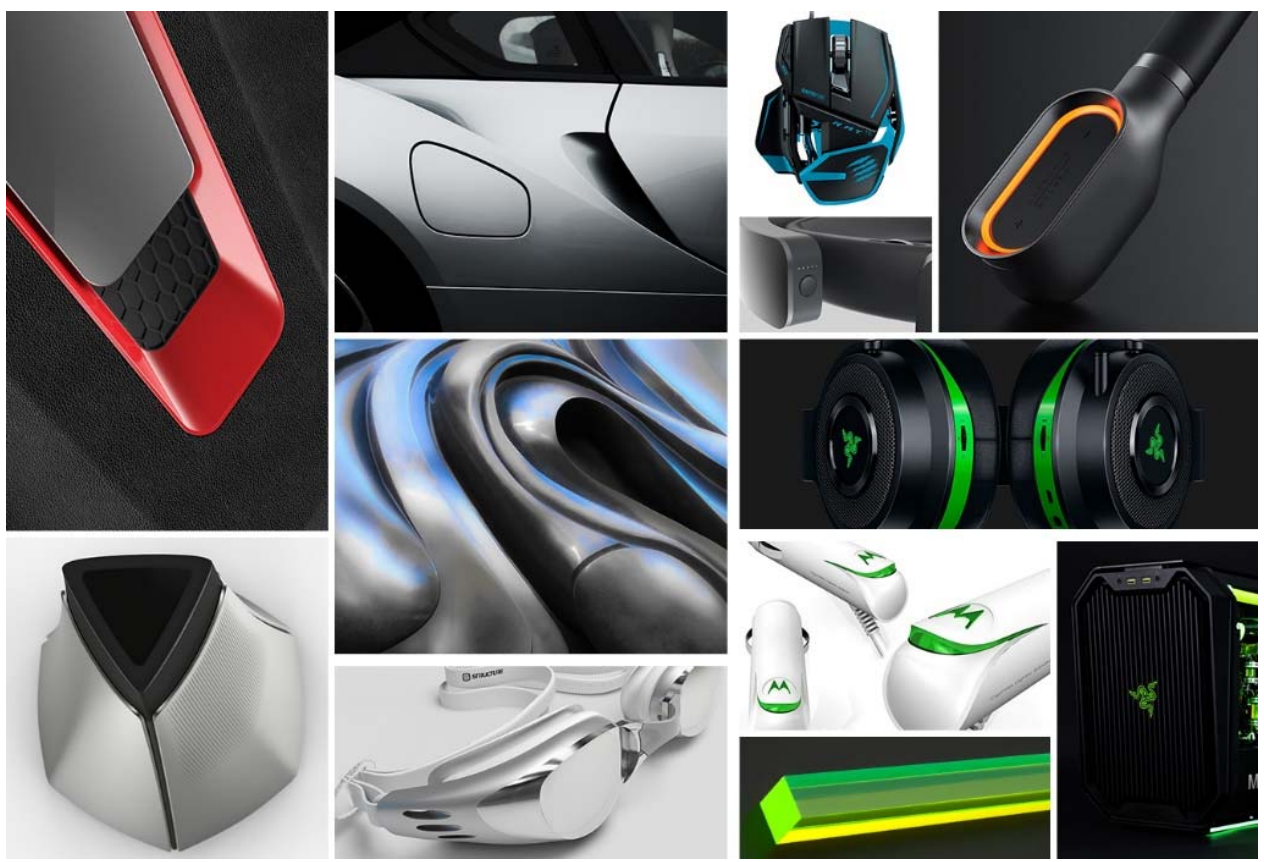

Fonte: o autor

\subsection{Fase da geração}

Após as análises e definições dos objetivos apresentadas anteriormente, foi possível partir para a próxima etapa, a geração das alternativas para solução do problema.

\subsubsection{Capacete motociclístico}

Embora a proposta do projeto não seja o desenvolvimento de um capacete motociclístico e sim do sistema eólico para sinalização que será integrado a ele, foram realizados alguns esboços em papel como forma de geração de alternativas para o formato do casco em sua totalidade (figura 5). 
Figura 5 - Esboços dos detalhes do casco

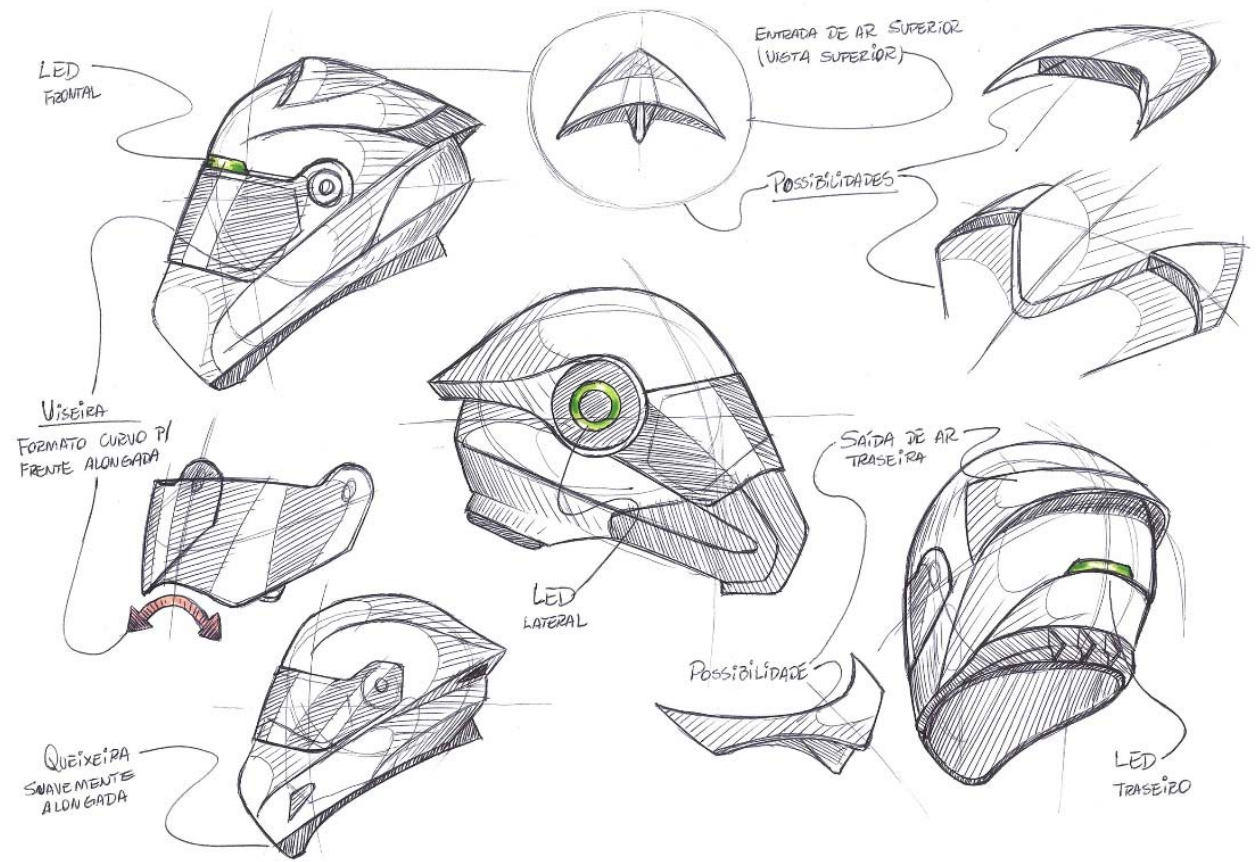

Fonte: o autor

Com base na definição da análise estrutural realizada na etapa anterior, de que o protetor do maxilar irá comportar o sistema eólico, a parte frontal do capacete foi ilustrada com a forma mais alongada, remetendo ao estilo cross, na qual se aumenta o espaço de acomodação do sistema. A viseira teria formato curvo em sua extremidade frontal para possibilitar melhor encaixe a forma alongada do protetor do maxilar. As possibilidades de entrada e saída de ar, possuindo formas triangulares para reforçar as linhas de aerodinâmica no casco. Algumas possibilidades de utilização do LED também foram ilustradas.

\subsubsection{Sistema eólico para sinalização}

Para acomodação do sistema eólico que vai proporcionar a sinalização do capacete, foram geradas três alternativas (figura 6). 
Figura 6 - Esboços das alternativas

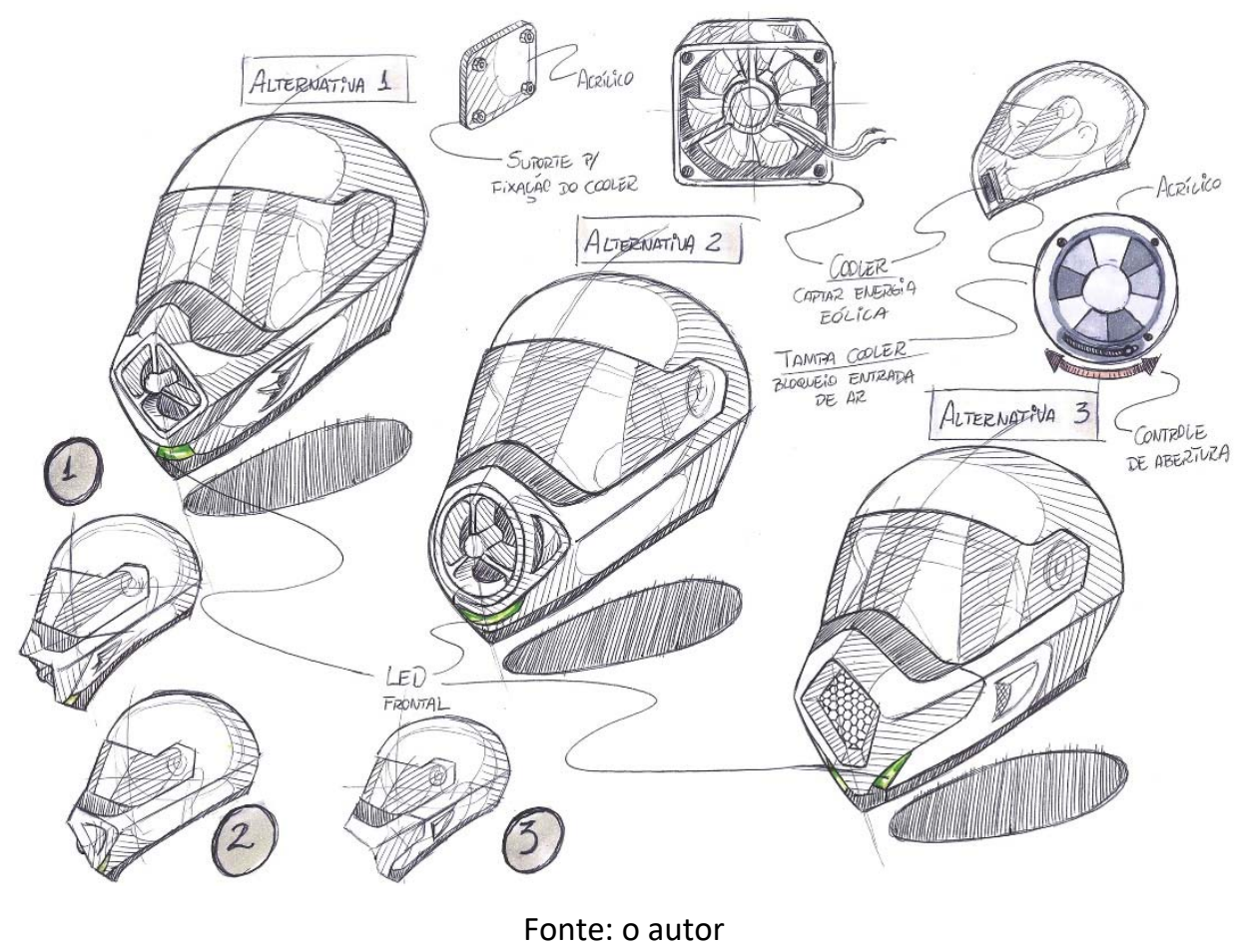

Todas as alternativas foram concebidas com o intuito de proporcionar que a entrada de vento fosse suficiente para o funcionamento do sistema.

A alternativa 1 foi gerada com referência a forma do cooler, possuindo no centro um cilindro de extremidade arredondada envolto por três hastes distribuídas em posição triangular. A frente alongada do protetor do maxilar tem formato losangular para acompanhar a silhueta do nariz do usuário.

A alternativa 2 possui características semelhantes a primeira, como a entrada de ar que também é dividida em três partes, diferenciando-se apenas por seu formato circular.

Por fim, a alternativa 3, diferentemente das outras que possuem hastes dividindo a entrada de ar em três partes, apresenta uma grade "colmeia" para uma única entrada de ar. Esta por sua vez, possui o formato de um pentágono alongado verticalmente, que assim como a alternativa 1, também acompanha a silhueta do nariz do usuário.

Pensando na utilização do produto em dias de chuva, gerou-se também o esboço de uma tampa de material plástico para bloquear a entrada de ar, evitando assim que a água possa atingir o rosto do usuário.

\subsection{Fase da avaliação}

Por meio da avaliação das alternativas foi possível realizar uma seleção da melhor alternativa gerada de acordo com os atributos estéticos e funcionais, para transformá-la no produto final.

Embora as alternativas elaboradas consistiram em variações do mesmo conceito, foram 
utilizados critérios objetivos para a escolha da alternativa mais promissora.

A alternativa 1, consiste em uma estrutura que além de possibilitar boa captação de energia eólica, apresenta uma forma que acompanha a silhueta do nariz do usuário, o que deixa mais evidente as linhas de aerodinâmica no capacete.

Já na alternativa 2 a aerodinâmica não está tão presente, devido a forma circular da entrada de ar, que apesar de também possibilitar boa captação de vento, tem um aspecto mais robusto e pouco harmonioso.

Observando a alternativa 3, percebe-se linhas de aerodinâmica próximas a alternativa 1 , contudo acredita-se que a entrada de ar seja de menor eficiência em relação as outras, pois a grade "colmeia" apresenta orifícios bem menores que reduzem a captação do vento.

Dessa forma, com base nos atributos estéticos e funcionais analisados, foi definido a alternativa 1 como a alternativa selecionada e a ser desenvolvida no seguimento do projeto.

\subsubsection{Detalhamento da alternativa selecionada}

O detalhamento da alternativa selecionada deu-se por meio de esboços (figura 7) refinando os detalhes de construção da peça, ilustrando o funcionamento e instalação do sistema eólico para sinalização, e também, o funcionamento dos orifícios de ventilação.

Figura 7 - Detalhamento da alternativa selecionada
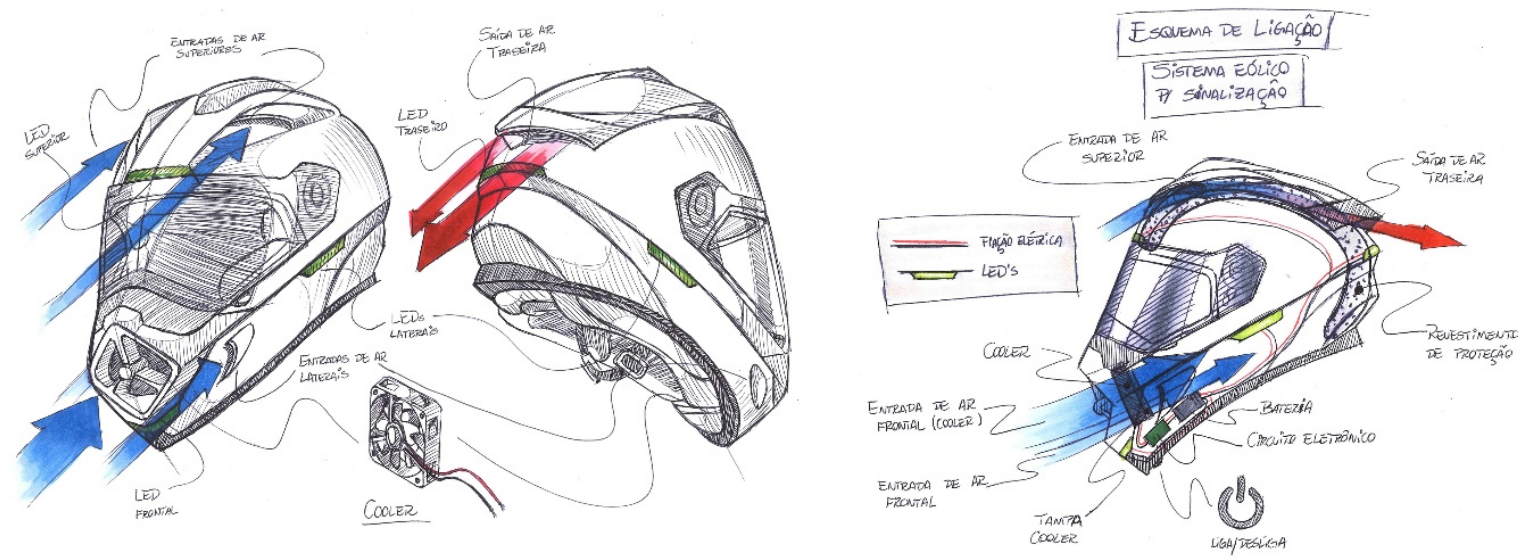

Fonte: o autor

\subsection{Fase de realização}

Nesta etapa foram realizados o refinamento dos detalhes do projeto mecânico e estrutural, por meio do desenvolvimento dos modelos tridimensional e físico.

\subsubsection{Modelagem tridimensional}

A modelagem tridimensional da alternativa final (figura 8) foi realizada utilizando-se o software 3ds Max 2016 da Autodesk, que permite a criação de modelos com formas orgânicas, como é o caso do capacete e renderizada utilizando-se os softwares SketchUp e V-Ray. 
Figura 8 - Modelo tridimensional da alternativa final

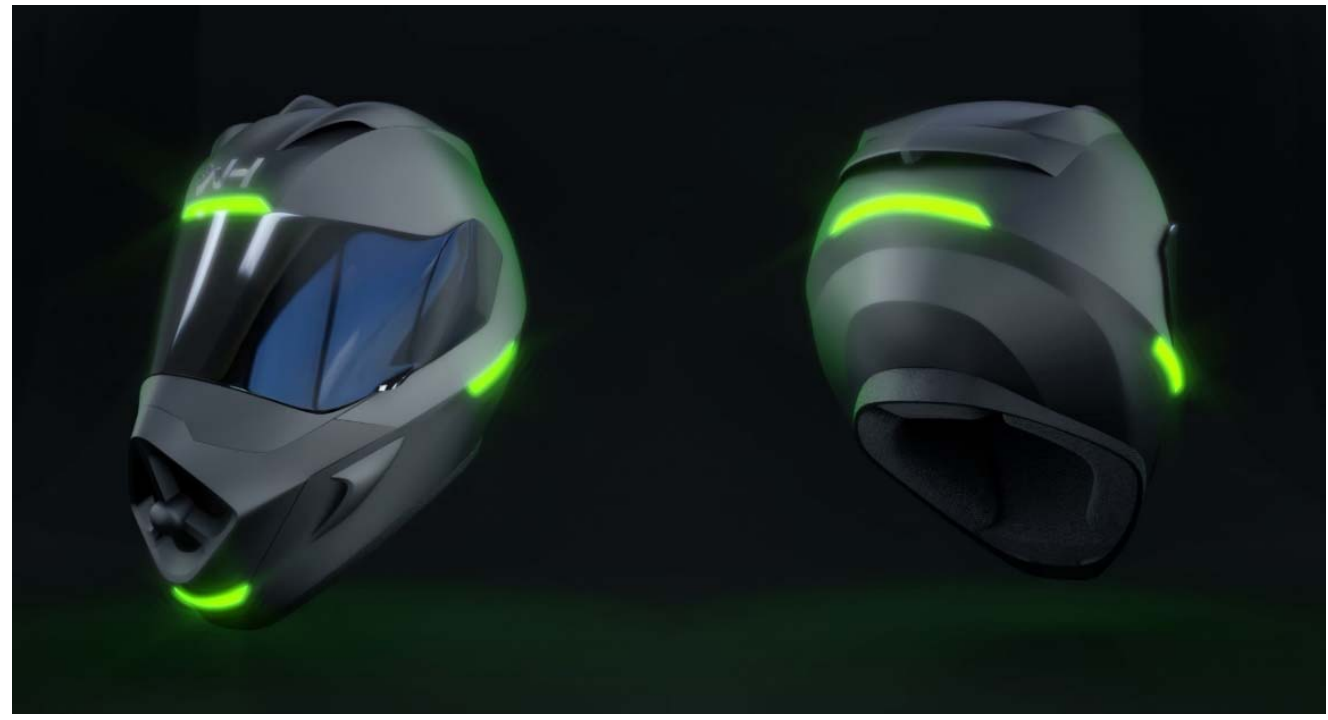

Fonte: o autor

\subsubsection{Modelagem física}

O modelo físico (figura 9) foi desenvolvido com a adaptação de um casco de capacete motociclístico inutilizado, para reaproveitá-lo como molde, ao qual foi adicionado uma mistura de espuma de poliuretano ( $P U A+B)$, conferindo a estrutura da peça. Optou-se em utilizar esse material, por ser de fácil moldagem e representar de modo bem próximo, o revestimento de proteção. Em seguida, foi aplicado massa plástica e massa de poliéster, para formar uma camada resistente e representar de maneira mais próxima, a estrutura do casco. A viseira foi confeccionada em acrílico e recoberta por insulfilm espelhado. Para os detalhes e acabamentos foram utilizados massa epóxi, massa rápida, primer e tinta em spray. Enfim, para finalizar, foram instalados os componentes do sistema eólico para sinalização.

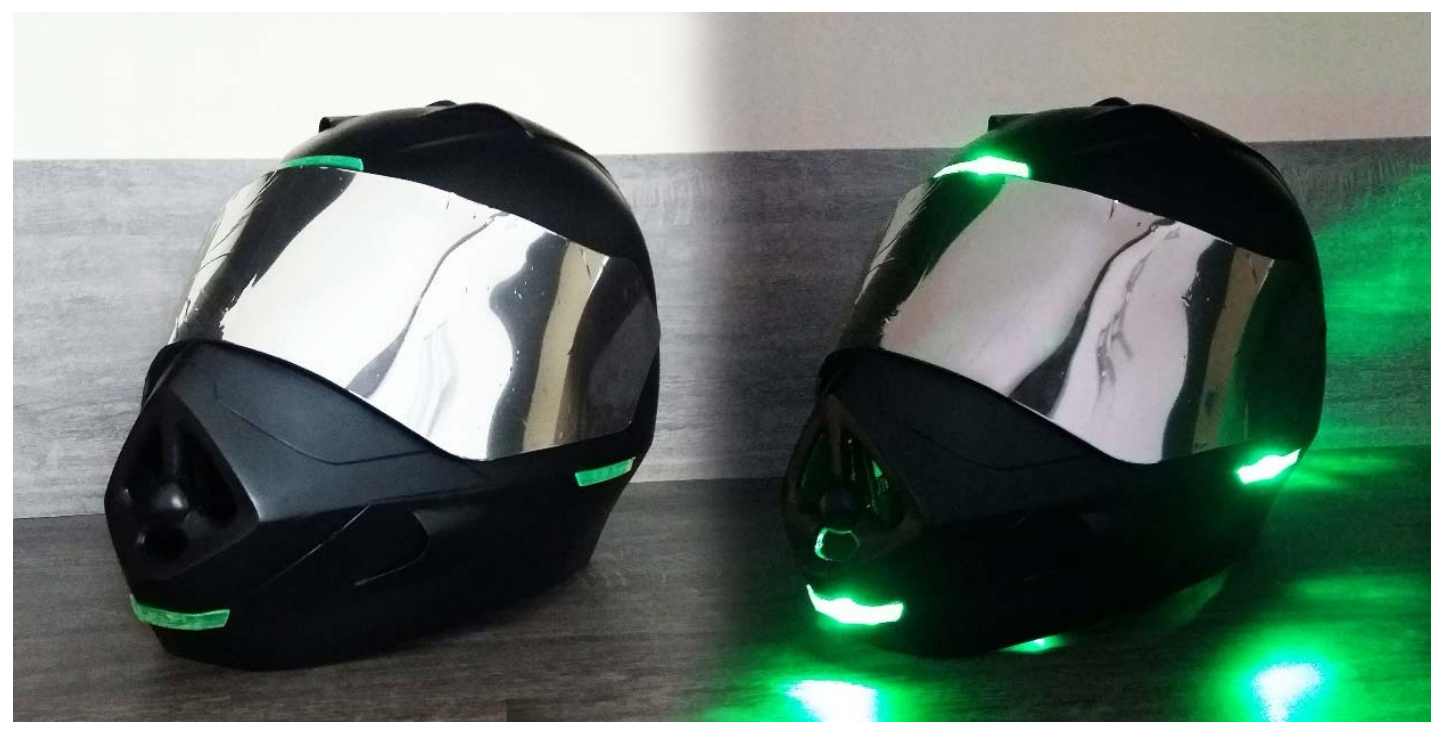

Fonte: o autor 


\section{Considerações Finais}

Na etapa de pesquisa, houve grande dificuldade para se encontrar informações técnicas e históricas sobre o capacete motociclístico e seu processo de fabricação. Muitas fontes para essas abordagens eram de origem estrangeira, implicando na tradução do conteúdo. De modo geral, a etapa de pesquisa atingiu seus objetivos, concluindo tópicos como: estrutura de construção do capacete, desenvolvimento histórico, ergonomia, legislação, conceitos de eletrônica, energia eólica e análise de similares, possibilitando a coleta de informações necessárias para o desenvolvimento do projeto.

$\mathrm{Na}$ fase relacionada ao desenvolvimento prático, os processos de modelagem tridimensional e modelagem física, também apresentaram algumas dificuldades. Para a modelagem tridimensional, o maior desafio foi transferir o desenho do capacete representado no papel para o software 3D, devido as suas formas orgânicas. Contudo, o resultado ficou como esperado. Já a modelagem física, exigiu grande empenho e dedicação, pois foi realizada manualmente. A primeira tentativa de construção do modelo, não foi bem-sucedida, pois não se utilizou um desmoldante para retirar a peça do molde, o que provocou danos em ambos, exigindo um novo material. Outra grande dificuldade foi o processo de desbaste para dar forma a peça, pois uma vez retirado material em excesso, fica inviável a recuperação. Por fim, o modelo físico ficou com dimensões divergentes do modelo tridimensional, mas transmite da maneira mais próxima possível, a ideia do projeto.

O sistema eólico para sinalização foi desenvolvido com base em conhecimentos de eletrônica. Antes da montagem dos componentes no modelo do capacete, foram realizados testes com o auxílio de um equipamento de medição específico em uma motocicleta, para comprovar o seu funcionamento de acordo com os objetivos pretendidos. Constatou-se que o veículo teve que atingir uma velocidade de aproximadamente $60 \mathrm{~km} / \mathrm{h}$ para que a energia eólica gerada fosse suficiente e possibilitasse a recarga da bateria do sistema.

Portanto, acredita-se que as atividades desenvolvidas até o momento, atingiram os objetivos esperados. Para um trabalho futuro, pretende-se realizar a modelagem tridimensional em um software específico, no qual seja possível analisar questões ergonômicas em relação ao ser humano, definir o tamanho ideal do capacete e o encaixe do sistema. Em seguida, a elaboração de um modelo físico em escala real, exibindo formas exatamente iguais ao modelo tridimensional, com o objetivo de avaliar as exigências ergonômicas, funcionais e a viabilidade técnica do projeto. 


\section{Referências}

BÜRDEK, Bernhard E. Design: História, Teoria e Prática do Design de Produtos. 1a Ed. São Paulo: Edgard Blücher, 2006.

CONTRAN. Conselho Nacional de Transito. Resolução 453: Disciplina o uso de capacete para condutor e passageiro de motocicletas, motonetas, ciclomotores, triciclos motorizados e quadriciclos motorizados. In: DENATRAN, 2013. (http://www.denatran.gov.br)

GOMES FILHO, João. Design do Objeto: Bases Conceituais. São Paulo: Escrituras, 2006.

IIDA, Itiro. Ergonomia: projeto e produção. $2^{\circ}$ Ed. São Paulo: Blucher, 2005.

KOTLER, Philip; KELLER, Kevin Lane. Administração de marketing. 12a Ed. São Paulo: Pearson Prentice Hall, 2006.

LÖBACH, Bernd. Design industrial: Bases para a configuração dos produtos industriais. 1a Ed. São Paulo: Edgard Blücher, 2001.

MUNARI, Bruno. Das coisas nascem coisas. 3a Ed. São Paulo: Martins Fontes, 2015. 